\title{
The use of modified triple-p method with adherent placenta long- term results
}

\begin{abstract}
At the article we represent the long-term results in 17 women who were operated using the modified technique of the Triple-P procedure with placenta percreta. Research was conducted with help of a specially designed questionnaire for patients and ultrasound examination of the wall uterus, especially of the anterior wall and the edge of postoperative scar. System analysis of literature data on this problem was conducted.
\end{abstract}

Keywords: massive obstetric hemorrhage, morbidly adherent placenta, peripartum hysterectomy, placenta percreta, triple-p procedure
Volume 4 Issue 2 - 2017

\author{
VB Tskhay, PK Yametov, NM Yametova \\ Krasnoyarsk State Medical University named after Prof.V.F.Voino \\ -Yasenetsky, Russia
}

\begin{abstract}
Correspondence: Tskhay Vitaly Borisovich, Head of the Department of Perinatology, Obstetrics and Ginecology, Medical Faculty Krasnoyarsk State Medical University named after Prof. V.F.Voino - Yasenetsky,Address: 660022, Str. P. Geleznyaka I, Krasnoyarsk, Russia, Tel 8(39I)2653584, +79232872134 Email tchai@yandex.ru
\end{abstract}

Received: January 12, 2017| Published: January 23, 2017

\section{Introduction}

"Morbidly adherent placenta" is a term that describes the continuum of placenta accreta, increta, and percreta. ${ }^{1}$ Placenta accreta is one of the most serious complications of pregnancy in connection with the development of massive intraoperative bleeding, high maternal morbidity and mortality, and a high frequency of hysterectomies. ${ }^{2-4}$ During caesarean section the volume of blood loss in placenta accreta is so great that it often exceeds several times the total blood volume of the patient. ${ }^{5-7}$ On the background of previously submitted data about a huge amount of blood loss in placenta accreta appear unique results presented by the English authors, which report about the development and implementation of their own new interdisciplinary methods, called "Triple-P". When using this method, the average intraoperative blood loss was $1440 \mathrm{ml}$ (ranges from $800 \mathrm{ml}$ to $2,900 \mathrm{ml}$ ). ${ }^{8,9}$ The operational technique of the "Triple-P" presented by English authors is safe and effective conservative surgical alternative to hysterectomy in case of placenta previa accreta. This procedure involves performing three positions (three P-by the first three letters $\mathrm{P}$ from Latin alphabet): the first P-perioperative placental localization and delivery of the fetus via transverse uterine incision above the upper border of the placenta; the second $\mathrm{P}$ is devascularization of the uterus by fanning the air pre-placed under the $\mathrm{x}$-ray control special cylinders in both arteries internal iliac; the third P-placental non-separation with myometrial excision and reconstruction of the uterine.

\section{Materials and methods}

The study was conducted at the Krasnoyarsk regional clinical perinatal center (affiliated with Krasnoyarsk Medical University) where for the period 2013-2016 were operated 281 patients with placenta previa. The "Triple-P" surgery is being used in our clinic since June 2014. The author's method of the "Triple-P" procedure was modified in our clinic into the method of devascularization of the uterus with doing clamping procedure instead of performing balloon occlusion of internal iliac arteries. We do that as balloon occlusion of internal iliac arteries is still not available even in some clinics of the 3-d level. So, using a modified method of "Triple-P," we operated 35 patients with placenta previa percreta. We have studied the long-term results in 17 women who were operated using the modified technique of the "Triple-P" with placenta percreta (Figure 1). The time elapsed since the operation ranges from 8 to 24 months. All the operated patients answered the questions of a specially designed questionnaire to assess quality of their life, menstrual and sexual function, and future reproductive plans. They all underwent targeted ultrasound examination of the wall uterus, especially of the anterior wall and the edge of postoperative scar.

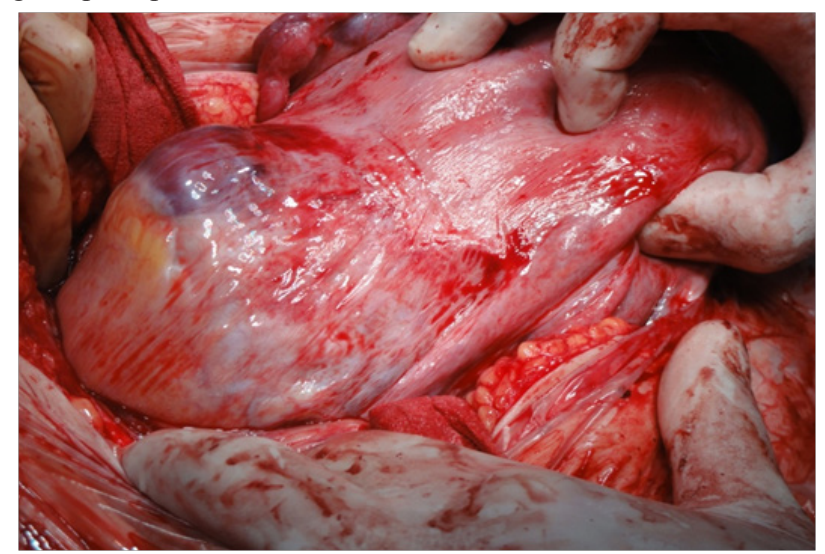

Figure I Placenta previa percreta.

\section{Results and discussion}

Up to the regional guideline of Krasnoyarsk Health Ministry, all pregnant women diagnosed with placenta previa should be referred to the Regional clinical perinatal center as the institution of the $3^{\text {rd }}$ level. The frequency of placenta previa from the total number of births for the period January $1^{\text {st }}, 2013$ - December 31 st, 2016 is $2.1 \%$, while the frequency of placenta accreta was $0.3 \%$ Table 1. Average women's age $31,8 \pm 4,0$ (from 23 to 41 ). The average number of pregnancies in the medical record was $4.2 \pm 1,5$ (from 2 to 13 ), the average birth parity was $2.7 \pm 1,1$ (from 1 to 11 ). Method of delivery in the majority of patients in previous pregnancies was caesarean delivery - $82,4 \%$ $(\mathrm{n}=14)$, while $23.5 \%(\mathrm{n}=4)$ cases - two cesarean deliveries, and in $5.9 \%(n=1)-5$ caesarean sections. Gestational period at the time of delivery was an average $34.3 \pm 2.1$ weeks ( 28 to 38 ). The proportion of 
preterm delivery before 37 weeks amounted to $82.4 \%(n=14)$. There were no cases of perinatal losses. The mean duration of operation was $102,9 \pm 21.2 \mathrm{~min}$ (65 to 173 ), the average intraoperative blood loss-2423, $5 \pm 854 \mathrm{ml}$ (from 980 to $4,100 \mathrm{ml}$ ). In the process of the surgery, following its third principle (P)- myometrial excision and reconstruction of the wall uterine we removed a large section of the affected tissue of the anterior wall of the uterus at the location of placenta percreta. The size of these "uterine hernias" varied from $10 \times 6 \mathrm{~cm}$ to $14 \times 16 \mathrm{~cm}$. Due to this excision, the data of anatomical and functional condition of the uterus in post- surgery period presented a great interest to us. In average the duration of hospital stay of patients after the operation was $8.2 \pm 1.9$ days (ranges from 5 to 18). Among the postoperative complications there was reported 1 injure of the bladder, one case of the developed hematometra on the 5th postoperative day, 1 case of postpartum endometritis with antibiotic treatment. Up to the survey all the operated patients mentioned restoration of regular menstrual cycle. $4(23.5 \%)$ women reported slightly more abundant menstrual flow, and two patients $(11,7 \%)$ noted algomenoreya. One patient from time to time suffered from painful and difficult urination, and one patient had some signs of vaginal dysbiosis. 2patients (11,7\%) reported some change in the quality of sexual life and the other 2- pain during an intercourse; decreased libido-1 patient $(5,8 \%)$.

During surgery most patients (15 of 17) have refused to undergo surgical sterilization, though in two cases this surgery was performed. At the same time, $11(64,7 \%)$ patients did not plan future pregnancy, $3(17,6 \%)$ patients replied that they were not sure in their intentions and only $3(17.6 \%)$ patients are set up on having children in the future. Despite the high percentage of premature births, there were no significant violations in the future development of their children. In $76.5 \%$ of cases $(n=13)$ mothers assessed their child development as successful and 23.6\% $(\mathrm{n}=4)$ - satisfactory. Duration of breastfeeding averaged $6.0 \pm 4.5$ months ( 15 days to 15 months). 3 women continued breastfeeding up to the time of the survey. Complications - up to the sonography investigation -in $94.1 \%$ of cases $(n=16)$ the size of the uterus was within normal limits and uterus structure was typical (Figure 2), in one case $(5,8 \%)$ uterine size had been increased due to the presence of uterine myoma. In $76.4 \%$ of cases $(n=13)$ typical postoperative scar on the anterior wall of the uterus was visualized, in $23.5 \%$ of the cases $(n=4)$ the scar in the myometrium was not visible. In $17.6 \%$ of the cases $(n=3)$ there are some structural changes in the anterior wall of myometrium, the so-called symptom of "niche" (Figure 3). In these cases, the thickness of the myometrium above the niche was $4 \mathrm{~mm}, 3.3 \mathrm{~mm}$ and $2.3 \mathrm{~mm}$.

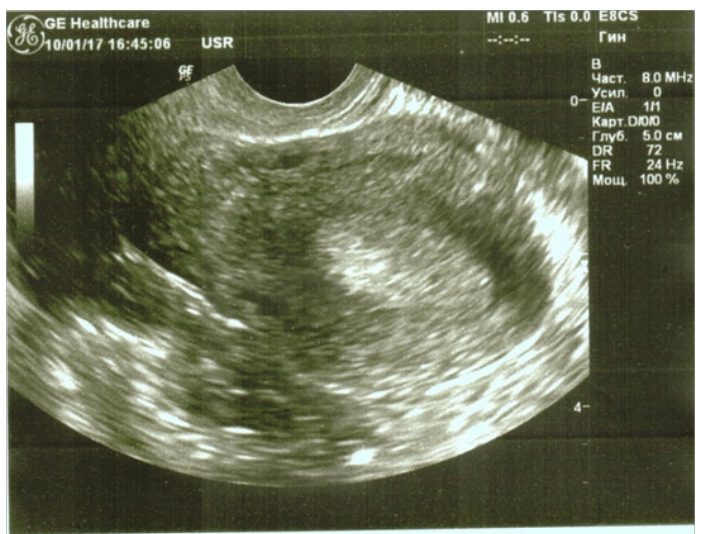

Figure 2 Ultrasound diagnostic 10 months post operation time (Triple-P procedure). Normal uterine structure.

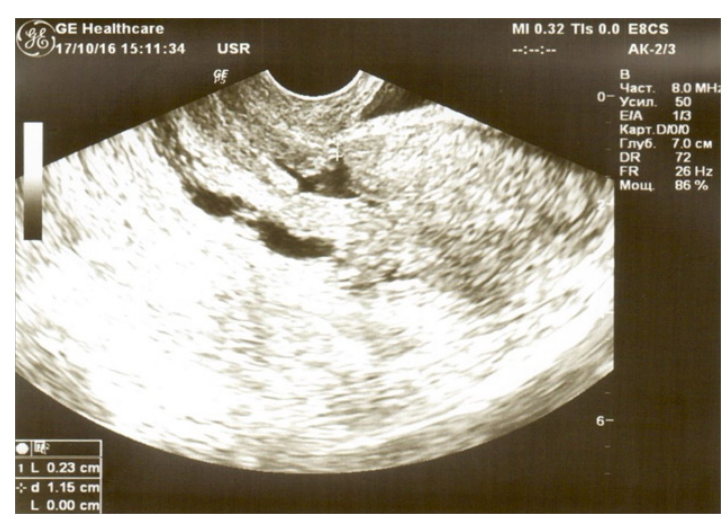

Figure 3 Ultrasound diagnostic 9 months post operation time (Triple-P procedure). Symptom of niche.

Table 1 Incidence of occurrence of adherent placenta, blood loss, frequency of hysterectomies and operations the "Triple - P" for the period from 2013 to 2016

Incidence leve

2013

2014

2015

2016

The total number of births(abs)

304

3053

3307

3562

The frequency of placenta previa from the total $52(1,71 \%) \quad 55(1,80 \%) \quad 97(2,99 \%)$ $82(2,30 \%)$ number of births(abs/\%)

\section{The frequency of} placenta percreta from the total number of $10(0,32 \%)$ $20(0,61 \%)$ $22(0,62 \%)$ births(abs/\%)

Blood loss more than $1500 \mathrm{ml}$ in patients with placenta previa(abs/\%)

$26(50,0 \%) \quad 3970,91 \%) \quad 50(34,2 \%)$

$30(36,58 \%)$

The frequency of hysterectomies in patients with placenta previa perceta(abs/\%)

The number of operations the "Triple P"(abs)

The frequency of hysterectomies in the procedure of "Triple $4(100 \%)$ $4(40,0 \%)$ $4(20,0 \%)$ $9(40,9 \%)$ P"(abs/\%)

\section{Conclusion}

The present article describes long- term results of the Triple-P procedure, which involves perioperative placental localization and delivery of the fetus via transverse uterine incision above the upper border of the placenta; pelvic devascularization and placental non- 
separation with myometrial excision and reconstruction of the uterine wall. This technique appears a safe and effective alternative to hysterectomy. The data obtained showed that the use of the Triple-P procedure allowed not only to preserve the uterus in young women, but also to provide them a fairly high level of quality of life and reproductive health. The long - term results, characterizing the reproductive health of women who had undergone organ-preserving operations for the placenta adherents, indicate the prospects of this direction and require its further improvement and development. Since we obtained the study data which include a small number of cases, to obtain reliable results requires further study and generalization of data obtained from different medical centers.

\section{Acknowledgements}

None.

\section{Conflict of interest}

The author declares no conflict of interest.

\section{References}

1. Baird SM, Troiano NH, Kennedy MB. Morbidly adherent placenta: interprofessional management strategies for the intrapartum period. $J$ Perinat Neonatal Nurs. 2016;30(4):319-326.

2. Tapisiz OL, Altinbas SK, Yirci B, et al. Emergency peripartum hysterectomy in a tertiary hospital in Ankara, Turkey: a 5-year review. Arch Gynecol Obstet. 2012;286(5):1131-1134.
3. Evsen MS, Sak ME, Soydine HE, et al. Retrospective analysis of placenta accreta: management strategies - evaluation of 41 cases. Ginekol Pol. 2012;83(7):501-504.

4. Ortiz Villalobos RC, Bañuelos-Franco A, Serrano-Enriquez RF, et al Obstetric hysterectomy in patients with accreta, increta and percreta placentae: comparison of two surgical techniques. Ginecol Obstet Mex. 2016;84(4):209-216.

5. Wright JD, Pri Paz S, Herzog TJ, et al. Predictors of massive blood loss in women with placenta accreta. Am J Obstet Gynecol. 2011;205(1):38. e1-38.e6.

6. Grace Tan SE, Jobling TW, Wallace EM, et al. Surgical management of placenta accreta: a 10-year experience. Acta Obstet Gynecol Scand. 2013;92(4):445-450.

7. Sumigama S, Itakura A, Ota $\mathrm{T}$, et al. Placenta previa increta/percreta in Japan: a retrospective study of ultrasound findings, management and clinical course. J Obstet Gynaecol Res. 2007;33(5):606-611.

8. Chandraharan E, Rao S, Belli AM, et al. The Triple-P procedure as a conservative surgical alternative to peripartum hysterectomy for placenta percreta. Int J Gynaecol Obstet. 2012;117(2):191-194.

9. Chandraharan E. Should the Triple-P procedure be used as an alternative to peripartum hysterectomy in the surgical treatment of placenta percreta? Womens Health. 2012;8(4):351-353. 